\title{
UTILIZAÇÃO DE UM SISTEMA DE PROVAS ELETRÔNICAS (SPE) COMO ESTRATÉGIA DE ENSINO E AVALIAÇÃO DE APRENDIZAGEM: UM ESTUDO DE CASO EM UMA INSTITUIÇÃO DE ENSINO SUPERIOR (IES)
}

\author{
USE OF AN ELECTRONIC EXAMINATION SYSTEM (SPE) \\ AS A STRATEGY FOR TEACHING AND EVALUATION OF \\ LEARNING: A CASE STUDY AT AN INSTITUTION OF \\ HIGHER EDUCATION (IES)
}

Data de submissão: 11-03-2013 Aceite: 11-06-2014

Vinicius Costa da Silva Zonatto ${ }^{1}$ Elvis Silveira-Martins ${ }^{2}$ Andréia Carpes Dani ${ }^{3}$ Roberto Carlos Klann ${ }^{4}$

\section{RESUMO}

O estudo objetiva identificar as contribuições de um Sistema de Provas Eletrônicas (SPE) nos processos de ensino e avaliação da aprendizagem dos acadêmicos dos cursos de graduação presenciais em Administração e Ciências Contábeis de uma instituição de ensino superior. Um estudo de caso, de natureza exploratória e descritiva, com abordagem qualitativa e quantitativa dos dados foi realizado. As principais contribuições destacadas pelos docentes nos processos de ensino e avaliação da aprendizagem estão relacionadas à identificação de áreas de melhoria, o reforço de conteúdos ministrados durante o curso, a consolidação de conceitos básicos, a ampliação dos conhecimentos gerais (aprendizagem multidisciplinar), maior qualidade de ensino e melhores níveis de aprendizagem. Os resultados encontrados mostram que o desempenho dos alunos nas avaliações do SPE foi crescente, o que representa um melhor desempenho de todo o grupo analisado. Resultados similares foram observados nas avaliações bimestrais, em que o desempenho dos alunos também foi crescente e o desvio padrão menor, o que indica menor dispersão no desempenho geral dos alunos. Os resultados encontrados sugerem que os alunos observados estão alcançando melhor aprendizado de todo o conteúdo ministrado nos cursos, o que abre perspectivas para um novo campo de investigação. Conclui-se que o SPE pode ser uma eficiente estratégia de ensino e avaliação de aprendizagem.

Palavras-chave: Estratégias de ensino. Sistema de provas eletrônicas. Modalidade de avaliação. Aprendizagem acadêmica. Instituições de ensino superior.

\footnotetext{
1 Possui Graduação em Ciências Contábeis pela Universidade de Passo Fundo, UPF, Mestrado em Ciências Contábeis pela Fundação Universidade Regional de Blumenau, FURB e Doutorado em Ciências Contábeis e Administração pela Fundação Universidade Regional de Blumenau, FURB. Atualmente é Professor Permanente da FURB. Blumenau. Santa Catarina. Brasil. E-mail: viniciuszonatto@gmail.com 2 Possui Graduação em Administração de Empresas pela Universidade de Passo Fundo, UPF, Mestrado em Mestrado em Administração pela Universidade do Vale do Itajaí, UNIVALI e Doutorado em Administração e Turismo pela Universidade do Vale do Itajaí, UNIVALI. Pelotas. Rio Grande do Sul, brasil. E-mail: elvisprofessor@gmail.com

3 Possui Graduação em ciencias contábeis pela Universidade Regional Integrada do Alto Uruguai e das Missões, URI, Mestrado em Ciências Contábeis pela Fundação Universidade Regional de Blumenau, FURB e Doutorado em andamento em Ciências Contábeis pela Fundação Universidade Regional de Blumenau, FURB. Blumenau. Santa Catarina. Brasil. E-mail: andreiacarpesdani@gmail.com

4 Possui Graduação em Ciências Contábeis pela Fundação Universidade Regional de Blumenau, FURB, Mestrado em Ciências Contábeis pela Fundação Universidade Regional de Blumenau, FURB e Doutorado em Doutorado em Ciências Contábeis e Administração pela Fundação Universidade Regional de Blumenau, FURB. Atualmente é Professor Titular do Curso de Ciências Contábeis do Centro Universitário de Brusque (Unifebe). Blumenau. Santa Catarina. Brasil. E-mail: rklann@furb.br
} 


\begin{abstract}
This study aims to identify the contributions of an Electronic Examination System of (SPE) in the processes of teaching and learning evaluation of Business and Accounting Undergraduate students of a higher education institution. A case study, of exploratory and descriptive nature, with qualitative and quantitative approach was conducted. The main highlighted contributions by teachers in the teaching and evaluation of learning processes are related to the identification of areas of improvement, the reinforcement of content taught during the course, the consolidation of basic concepts, the expansion of general knowledge (multidisciplinary learning), greater quality of education and higher levels of learning. The results show that the students' performance on the SPE assessments was increasing, which represents a better performance of the whole group analyzed. Similar results were observed in bimonthly evaluations, where the students' performance was also growing and lowest standard deviation, which indicates less dispersion in the overall performance of the students. The results suggest that the students' are getting a better learning the content taught in courses, which opens perspectives for a new field of research. It is concluded that the SPE can be an effective strategy of teaching and learning.

Keywords: Teaching strategies. System of electronic evidence. Method of examination. Academic learning. Institutions of higher education.
\end{abstract}

\title{
1 INTRODUÇÃO
}

Num contexto de globalização econômica e de aumento exponencial de competitividade, o processo de ensino-aprendizagem não se manteve estático, tornando-se flexível, ao mesmo tempo em que complexo. Neste sentido, observa-se que os alunos estão cada vez mais inseridos no universo tecnológico, vinculando-se também as especificidades de conhecimento que este ambiente the proporciona.

Diante deste cenário, a necessidade de transformações induz as instituições de ensino a uma visão que proporcione maior amplitude de seus horizontes pedagógicos, adequando suas estratégias de ensino para suprir as deficiências de conhecimento da demanda de alunos que lhe é apresentada. Deficiências de aprendizagem que é paradoxal, ao mesmo tempo em que os alunos recebem um excesso de informação e pouca é retida ou aproveitada como sendo conteúdo útil para a vida (PINTO, 2001).

No Brasil, de acordo com a Lei n. 9.394/1996, que estabelece as Diretrizes e Bases da Educação Nacional (LDB), as instituições de ensino superior (IES) objetivam "formar diplomados nas diferentes áreas do conhecimento, aptos para inserção em setores profissionais e para a participação no desenvolvimento da sociedade brasileira", colaborando ainda na sua formação contínua. Assim sendo, por meio das matrizes curriculares dos cursos de graduação, as IES definem o conjunto de disciplinas que irão caracterizar determinado curso (PIRES, OTT, DAMACENA, 2010).

No entanto, esta necessidade de formação de profissionais com amplos conhecimentos em determinada área exige das IES o desenvolvimento de estratégias de ensino e avaliação de aprendizagem que proporcionem maior maximização deste processo, ou seja, que resulte em maior absorção dos conteúdos ministrados durante o curso. De acordo com Vygotsky (1978), a aprendizagem acontece no intervalo entre o conhecimento real e o conhecimento potencial.

Desta forma, os esforços desenvolvidos pelas instituições de ensino e professores em geral, devem ser empreendidos também de forma a oportunizar condições de autoavaliação da aprendizagem, bem como, o reforço dos conteúdos já ministrados. Tais ações podem contribuir para a absorção dos conteúdos que se encontram em processo de amadurecimento, conforme destacado por Vygotsky (1978), aumentando assim os níveis de aprendizagem dos alunos.

Nesta perspectiva, uma das alternativas encontradas pelas IES no desenvolvimento de estratégias de ensino que busquem maximizar o aprendizado acadêmico, está relacionada à utilização de tecnologias da informação nas metodologias de ensino, como ambientes virtuais de aprendizagem (PAL- 
UTILIZAÇÃO DE UM SISTEMA DE PROVAS ELETRÔNICAS (SPE) COMO ESTRATÉGIA DE ENSINO E AVALIAÇÃ̃O DE APRENDIZAGEM: UM ESTUDO DE CASO EM UMA INSTITUIÇÃO DE ENSINO SUPERIOR (IES)

LOFF; PRAT, 1999; SILVA, 2003; BARBOSA, 2005) ou ambientes multimídia (LEVY, 1999; FAHY, 2004). De acordo com Clark (1983) as tecnologias devem ser empregadas como conjunções para prover a aprendizagem. Desta forma, as tecnologias da informação também podem ser consideradas estratégias de ensino, se utilizadas de maneira adequada, facilitando a aprendizagem dos alunos (BERNSTEIN, 2001; HANSON; ROBSON, 2004; YOHON; ZIMMERMAN; KEELER, 2004; PARKER; BIANCHI; CHEAH, 2008).

Mazzioni (2013, p. 2) explica que o termo "estratégias de ensino refere-se aos meios utilizados pelos docentes na articulação do processo de ensino, de acordo com cada atividade e os resultados esperados". Assim sendo, no contexto de atuação das instituições de ensino superior, as estratégias de ensino podem ser compreendidas como o conjunto de atividades desenvolvidas e utilizadas pelos professores durante os processos de ensino, buscando promover a aprendizagem dos alunos. Tais processos envolvem todos os diferentes métodos e técnicas de ensino utilizadas por professores e instituição.

Como parte integrante desses métodos e técnicas de ensino, a "tecnologia da informação (TI) está desempenhando crescentemente um papel de maior importância no setor de ensino. A utilização de ferramentas tecnológicas tem possibilitado uma maior disponibilização de ferramentas de apoio didático" (ANJOS; CASTRO, 2007 p. 4). Bernstein (2001) explica que as tecnologias da informação podem influenciar a aprendizagem, assim como a forma como os professores ministram suas disciplinas.

Neste contexto, busca-se neste estudo, investigar: Quais as contribuições obtidas nos processos de ensino e avaliação do aprendizado de acadêmicos dos Cursos de Graduação presenciais em Administração e Ciências Contábeis de uma instituição de ensino superior mediante a implantação de um Sistema de Provas Eletrônicas (SPE)? O propósito central do estudo consiste em identificar as contribuições de um Sistema de Provas Eletrônicas (SPE) nos processos de ensino e avaliação da aprendizagem de acadêmicos dos Cursos de Graduação presenciais em Administração e Ciências Contábeis de uma instituição de ensino superior.

De forma mais específica busca-se: a) verificar o percentual de alunos que realizaram as referidas avaliações no período objeto de estudo; b) analisar a evolução do desempenho acadêmico desses alunos nas avaliações do SPE e avaliações bimestrais (provas) das disciplinas; e, c) investigar a percepção dos docentes dos cursos pesquisados sobre o Sistema de Provas Eletrônicas e sua influência no ensino e aprendizado dos acadêmicos. Adicionalmente, destaca-se que o SPE é uma modalidade de avaliação eletrônica, do tipo prova, desenvolvida pela Faculdade denominada neste estudo como Motivação, que complementa a avaliação das disciplinas dos respectivos cursos. Esta avaliação abrange questões de todas as disciplinas já cursadas pelos alunos.

O estudo justifica-se por fornecer evidências que contribuem para o entendimento de como a utilização de um sistema de provas eletrônicas pode contribuir no processo de ensino e na melhoria dos níveis de aprendizagem dos acadêmicos. De acordo com Liu, Timothy e Gao (2010), poucos são os estudos que fornecem evidências das contribuições da TI nos processos de gestão das organizações. Evidências anteriores sugerem que a utilização de recursos tecnológicos contribui com a melhoria dos processos de gestão organizacional (O'BRIEN, 2002; KEARNS; SABHERWAL, 2006; ZHANG, 2007), bem como, a melhoria do aprendizado acadêmico (BERNSTEIN, 2001; HILLS; TEDFORD, 2003; HANSON; ROBSON, 2004; YOHON; ZIMMERMAN; KEELER, 2004; PARKER; BIANCHI; CHEAH, 2008; VARIS, 2007; BEAK; JUNG; KIM, 2008; LONN; TEASLEY, 2009).

Além disto, Hocayen-da-Silva, Castro e Maciel (2008) chamam a atenção para a necessidade do desenvolvimento de novas tecnologias de ensino, que possam contribuir para a melhoria da qualidade do ensino no Brasil. Desta forma, observa-se a necessidade de se identificar como novas alternativas de ensino e avaliação de aprendizagem como um sistema de provas eletrônicas (SPE), podem contribuir para a melhoria dos processos de ensino-aprendizagem, tendo por base a realidade dos discentes e a adaptação de novas tecnologias no ensino das IES. O trabalho está estruturado em cinco seções. Inicialmente apresenta-se a introdução desenvolvida para a 
pesquisa. A seguir, a fundamentação teórica utilizada para suportar a realização deste estudo. Na sequência, descrevem-se o método e os procedimentos da pesquisa. Por fim, são apresentados os resultados, as considerações finais e as recomendações para estudos futuros.

\section{FUNDAMENTAÇÃO TEÓRICA 2.1 Teoria Sociointeracionista de Vygotsky}

Os processos de ensino e avaliação de aprendizagem são objetos de estudo em diferentes áreas do conhecimento (LANTOLF; PAVLENKO, 1995; DUNN; LANTOLF, 1998; SPOUSE, 1998; TAPPAN, 1998; KILGORE, 1999). Entretanto, as principais teorias de aprendizagem desenvolvidas para sua análise e interpretação são advindas do campo de estudos da psicologia e da educação. Uma das teorias de aprendizagem mais utilizadas para a realização de estudos com este foco de investigação é a Teoria Sociointeracionista de Vygotsky (CHAIKLIN, 2003).

Esta teoria procura explicar o aprendizado em um contexto de interação social. A interação social compreende todo o processo de troca de experiência, informação e objetivos. Assim, é a partir desta interação que se formam os processos de aprendizagem (VYGOTSKY, 1978). De acordo com os estudos de Vygotsky $(1963 ; 1967 ; 1973 ; 1978)$, o desenvolvimento sócio cognitivo é desencadeado a partir das interações observadas entre os indivíduos e o meio. Nesta perspectiva, é o próprio processo de aprendizagem que gera e promove o desenvolvimento das estruturas mentais superiores.

Zanella (1994, p. 98) explica que a teoria de Vygotsky considera que o desenvolvimento e a aprendizagem inter-relacionam-se desde o nascimento da criança, isto é, a constituição do sujeito é um movimento dialético entre aprendizagem e desenvolvimento. Segundo Gomes et al. (2010, p. 699), para Vygotsky, "o aprendizado não é necessariamente precedido do desenvolvimento de bases psicológicas para tanto, mas se desenvolve em interação contínua. Da mesma forma, o aprendizado de um determinado assunto influencia o desenvolvimento do indivíduo além dos limites daquele assunto". Neste contexto, observa-se que os processos de aprendizagem são constantes e acompanham o indivíduo durante toda a sua vida.

O conceito central da Teoria Sociointeracionista de Vygotsky é a Zona de Desenvolvimento Proximal (ZDP). Para Vygotsky (1978) os processos de desenvolvimento e aprendizagem não são coincidentes. De acordo com o autor, o processo de desenvolvimento é anterior ao processo de aprendizagem. Esta sequência resulta no conceito de zonas de desenvolvimento proximal. Segundo Trinta (2009, p. 154), a Zona de Desenvolvimento Proximal atua como "uma ferramenta essencial que nos possibilita compreender as potencialidades dos indivíduos, o que está em processo de amadurecimento. Se bem trabalhada, nos possibilitará trabalhar satisfatoriamente com os alunos de modo a levá-los ao desenvolvimento constante".

A zona de desenvolvimento proximal pode ser exemplificada com o processo vivenciado por uma criança. De acordo com Vygotsky (1978), no momento em que uma criança assimila o significado de uma palavra, ou domina uma operação tal como a adição ou a linguagem escrita, seus processos de desenvolvimento estão apenas começando naquele momento. A principal consequência de se analisar o processo educacional desta maneira é mostrar que o domínio inicial de, por exemplo, as quatro operações aritméticas, fornece a base para o desenvolvimento posterior de uma variedade de processos internos altamente complexos no pensamento das crianças.

Conforme explica Vygotsky (1993, p. 239), "a zona de desenvolvimento proximal tem um valor mais direto para a dinâmica da instrução que o nível atual de seu desenvolvimento". Sob este aspecto, Facci et al. (2007, p. 325) comentam que "o processo de desenvolvimento segue o processo de aprendizado e este é o responsável por criar a zona de desenvolvimento proximal. Portanto, o ensino deve incidir sobre a zona de desenvolvimento proximal". Assim sendo, 


\begin{abstract}
A ZDP define as funções que ainda não amadureceram, mas estão em processo de amadurecimento, funções que amadurecerão amanhã, mas estão ainda em estado embrionário. O nível real de desenvolvimento caracteriza o desenvolvimento mental retrospectivamente, ao passo que a ZDP caracteriza-o de maneira futura, o que está por vir [...]. A ZDP nos permite delinear o futuro imediato da criança e seu estado de desenvolvimento dinâmico, mostrando-nos não somente o que já foi alcançado, mas o que está, também, em processo de amadurecimento (VYGOTSKY, 1978, p. 86).
\end{abstract}

Neste contexto, depreende-se que as estratégias de ensino implementadas pelas instituições de ensino superior também devem contemplar os processos de avaliação da aprendizagem, uma vez que por meio desta torna-se possível identificar, além dos níveis de aprendizagem dos alunos, os conteúdos que se encontram em processo de amadurecimento, ou seja, aqueles que demandarão maior tempo e esforço para serem absorvidos e compreendidos pelos alunos. Desta forma, torna-se possível o desenvolvimento de ações com vistas a estimular a aprendizagem destes conteúdos, maximizando assim os níveis de aprendizagem final dos alunos.

\title{
2.2 Estratégias de ensino utilizadas nos processos de ensino e aprendizagem
}

Os questionamentos emergentes da noção clássica de qualificação em todas as áreas de atuação estão relacionados à complexidade do mundo atual, que exige dos profissionais o desenvolvimento de um amplo conhecimento para lidar com a diversidade das situações de trabalho (PERRENOUD, 2002; LE BOTERF, 2003; SOARES; ARAÚJO; LEAL, 2012). A necessidade de formar profissionais com amplos conhecimentos desafia as metodologias tradicionais de ensino (LEÃO, 1999).

Assim, atrelam-se as mudanças no papel da educação, na formação e na qualificação profissional advindas da competitividade, a necessidade de se identificar novas formas inovadoras de ensino que promovam a aprendizagem dos alunos (HOCAYEN-DA-SILVA; CASTRO; MACIEL, 2008; MORAIS; CABRITA, 2008). Nesse sentido, Ramos, Carvalho e Nascimento (2010, p. 2) explicam que as inovações foram acentuadas em período recente como consequência do fenômeno da globalização e o forte desenvolvimento tecnológico que proporcionou maior agilidade e acesso a informações.

De acordo com Araújo, Santana e Ribeiro (2009, p. 2), “o processo de ensino deve ser um facilitador da aprendizagem utilizando-se para tanto de meios e estratégias a fim de se atingir os objetivos educacionais, onde está inserida a aprendizagem". Por consequência, "o processo de aprendizagem é uma resposta do indivíduo ao estímulo do ambiente diante de uma situação-problema, considerando-se os hábitos e aspectos da vida deste indivíduo". Assim, um processo relaciona-se com o outro.

De maneira geral, diversos são os fatores que podem de alguma forma interferir nos resultados esperados no processo de ensino-aprendizagem, como por exemplo, a influência do cenário sócio-político sobre o ensino, as condições estruturais da instituição de ensino e os recursos disponíveis, as condições de trabalho dos docentes (MAZZIONI, 2013), o relacionamento professor-aluno, a capacidade dos docentes em motivar e sensibilizar os alunos (MORAN, 1997), assim como a própria condição social do aluno (MAZZIONI, 2013).

Nesta perspectiva, entende-se que as estratégias de ensino utilizadas por professores e instituições ocupam um importante papel na relação ensino-aprendizagem. Por meio destas torna-se possível desenvolver um ambiente criando condições que possam facilitar a aprendizagem dos alunos. Buscando-se identificar as principais estratégias de ensino utilizadas nos processos ensino-aprendizagem, elaborou-se o Quadro 1, apresentado a seguir. 


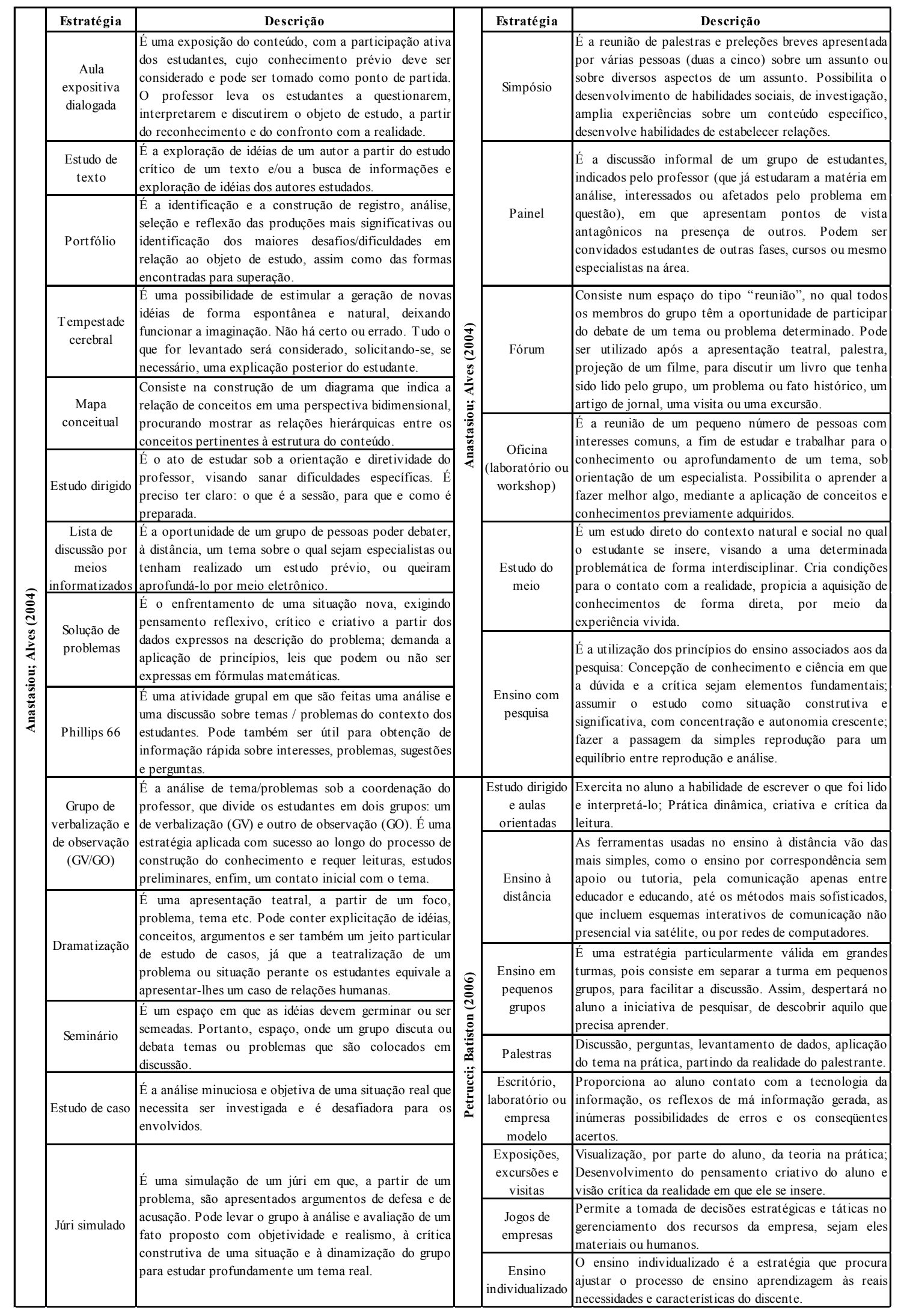

Quadro 1 - Definição das estratégias de ensino no processo de Ensino e Aprendizagem

Fonte: Adaptado de Mazzioni (2013) 
UTILIZAÇÃO DE UM SISTEMA DE PROVAS ELETRÔNICAS (SPE) COMO ESTRATÉGIA DE ENSINO E AVALIAÇÃ̃O DE APRENDIZAGEM: UM ESTUDO DE CASO EM UMA INSTITUIÇÃO DE ENSINO SUPERIOR (IES)

Destacando o papel das estratégias de ensino neste processo, Anastasiou e Alves (2004, p. 71) explicam que as estratégias visam à consecução de objetivos, e por esse motivo é preciso ter clareza sobre aonde se pretende chegar num determinado momento com o processo de aprendizagem. "Por isso, os objetivos que norteiam as atividades de ensino devem estar claros para os sujeitos envolvidos - professores e alunos - e estar presentes no contrato didático, registrado no Programa de Aprendizagem correspondente ao módulo, fase, curso, etc...". Tais ações podem facilitar o ambiente de aprendizagem.

Nesse sentido, Mazzioni (2013) destaca que cabe aos docentes estruturar sua didática a partir dessas informações, de forma a complementar as possibilidades que aumentem os resultados do processo de ensino-aprendizagem. A didática pode ser compreendida como a ciência e a arte de ensinar. Refere-se à metodologia e procedimentos utilizados pelo docente para direcionar e orientar o processo de aprendizagem (HAIDT, 2003).

$\mathrm{O}$ desenvolvimento de tais ações é convergente a abordagem teórica proposta por $\mathrm{Vy}$ gotsky. $O$ docente exerce um papel fundamental no processo de aprendizagem e, portanto, deve criar condições que proporcionem aos alunos momentos de autoavaliação, bem como, de desenvolvimento de conteúdos (FERNANDES, 2008). Esta interação contribuirá para o desenvolvimento de aprendizagem. Portanto, torna-se necessário o desenvolvimento contínuo de novas metodologias e técnicas de ensino que possam contribuir com a melhoria dos níveis de aprendizagem dos alunos (HOCAYEN-DA-SILVA; CASTRO; MACIEL, 2008).

A este respeito, Bernstein (2001) destaca que o uso de recursos tecnológicos deve ser explorado também neste processo, uma vez que por meio destes recursos é possível melhorar o desempenho dos alunos. Assim sendo, torna-se oportuno a realização de estudos que contribuam para o entendimento dos efeitos da influência do uso de recursos tecnológicos no processo de ensino-aprendizagem, razão pela qual se realiza este estudo.

\subsection{Utilização da TI nos processos de ensino e aprendizagem}

As discussões sobre novos processos de ensino e aprendizagem se encontram num contexto atual de reconhecimento e valorização. A busca por uma aprendizagem construída, contextualizada dentro de um cenário, promove a interação e a aprendizagem em comunidade (HILLS; TEDFORD, 2003). A tecnologia da informação e redes de informação tornaram a aprendizagem e o conhecimento independente das limitações de tempo e espaço. A informação é criada e distribuída globalmente on line via software social (VARIS, 2007, p. 18).

De acordo com Jonassen, Mayes e Mcaleese (1994) e Jonassen, Carr e Yueh (1998):

as tecnologias de informação e comunicação (TIC), entendidas como tecnologias educativas, são defendidas como podendo suportar de forma mais efetiva a construção de conhecimento no ensino superior e a promoção de aprendizagens relevantes, com sentido, em particular se utilizadas como ferramentas cognitivas de amplificação das capacidades mentais e não, como tradicionalmente acontece, apenas como meios de envio de informação, como comunicadores de conhecimento ou tutores de alunos (JONASSEN; MAYES; MCALEESE, 1994; JONASSEN; CARR; YUEH, 1998, citados por CARDOSO; PIMENTA; PEREIRA, 2008, p. 3).

Para Mendes Filho et al. (2001, p. 190), "a introdução de novas tecnologias na educação, principalmente associadas ao uso do computador, está provocando uma mudança no paradigma educacional". O foco está deixando de ser o ensino e passa a se centrar no aluno, na aprendizagem (ZHAO; HUEYSHAN; MISHRA, 2001; BEAK; JUNG; KIM, 2008). Quando o foco das ações do 
docente é direcionado ao ensino, a preocupação central está relacionada na melhor forma de se apresentar determinado conteúdo. No entanto, quando o foco passa a ser a aprendizagem, o docente preocupa-se em utilizar diferentes recursos, de forma complementar, os quais podem proporcionar uma maior absorção do conteúdo por parte do aluno, resultando em aprendizagem (ZHAO; HUEYSHAN; MISHRA, 2001; BEAK; JUNG; KIM, 2008).

Nesta perspectiva, Carvalho Júnior (2002; 2003) explica que a incorporação de recursos tecnológicos no cotidiano dos trabalhos acadêmicos permite a identificação de pontos que devem ser retrabalhados, a fim de viabilizar o aprendizado dos alunos. Anjos e Castro (2007) comentam que a utilização de tecnologias de informação no ensino está se tornando uma constante, como nas atividades de ensino à distância, conferências, disponibilização de material didático, treinamento, entre outros. Tais recursos estão contribuindo para a melhoria dos níveis de aprendizagem dos alunos, uma vez que oportunizam momentos de ensino e avaliação de aprendizagem (JONASSEN; MAYES; MCALEESE, 1993; JONASSEN, 1994; JONASSEN; CARR; YUEH, 1998; BERNSTEIN, 2001; HILLS; TEDFORD, 2003; VARIS, 2007; BEAK; JUNG; KIM, 2008; LONN; TEASLEY, 2009).

Apesar dos potenciais benefícios que podem ser obtidos com a utilização de recursos tecnológicos para o ensino e a aprendizagem, Litwin (2001, p. 85) destaca que "apenas o uso de meios tecnológicos de ensino não garante por si que os alunos ou alunas desenvolvam estratégias para aprender a aprender, nem incentivam o desenvolvimento das habilidades cognitivas de ordem superior". Segundo o autor, a qualidade educativa destes meios de ensino depende do uso e exploração didático-pedagógica realizada pelo docente e do contexto que se desenvolve a atividade.

Portanto, observa-se que os recursos tecnológicos devem ser utilizados de forma a complementar as estratégias de ensino e avaliação de aprendizagens utilizadas por docentes e instituições de ensino superior, fornecendo aos seus diferentes usuários (instituição, professores e alunos) informações referentes aos níveis de aprendizagem, os conteúdos com maiores níveis de absorção e os conteúdos que requerem maior esforço de docentes e discentes, a fim de viabilizar uma melhor aprendizagem e formação profissional dos acadêmicos.

O Quadro 2 apresenta uma síntese de alguns pontos a serem observados em relação à posição de professores e alunos, perante a utilização de novas tecnologias disponíveis para a realização dos processos de ensino e aprendizagem.

\begin{tabular}{|l|l|}
\hline $\begin{array}{l}\text { A posição do professor em relação às tecnologias no } \\
\text { ensino }\end{array}$ & $\begin{array}{l}\text { A posição do aluno em relação às tecnologias } \\
\text { no ensino }\end{array}$ \\
\hline $\begin{array}{l}\text { O professor precisa aprender uma maneira totalmente } \\
\text { nova de comunicar a mensagem e de garantir que a } \\
\text { aprendizagem aconteça usando as novas tecnologias } \\
\text { (Neto, 2000). }\end{array}$ & $\begin{array}{l}\text { Permite ao aluno ter acesso a informações a } \\
\text { qualquer momento e de qualquer lugar (Mendes } \\
\text { Filho et al., 2001). }\end{array}$ \\
\hline $\begin{array}{l}\text { O professor deve expor com mais recursos de tecno- } \\
\text { logias o conteúdo dado em sala de aula (Lima, Gomes; } \\
\text { Borges, 2000). }\end{array}$ & $\begin{array}{l}\text { Estimula o aluno a realizar mais pesquisas na } \\
\text { própria Internet a respeito dos assuntos estuda- } \\
\text { dos (Mendes Filho et al., 2001). }\end{array}$ \\
\hline $\begin{array}{l}\text { Através das tecnologias, o professor deve possibilitar } \\
\text { maior interação com o aluno (Lima; Gomes; Borges, } \\
2000) .\end{array}$ & $\begin{array}{l}\text { O ensino on-line elimina a inibição de certos alu- } \\
\text { nos, que sentem "vergonha", de expor suas per- } \\
\text { guntas em salas de aula, o que dificulta o apren- } \\
\text { dizado (Mendes Filho et al., 2001). }\end{array}$ \\
\hline $\begin{array}{l}\text { O professor deve permitir conciliar a exposição de de } \\
\text { conteúdo, de forma que a aula na Internet possa ser } \\
\text { a mesma da sala de aula (Lima; Gomes; Borges, 2000). }\end{array}$ & $\begin{array}{l}\text { Exclui a possibilidade de aula perdida, pois todas } \\
\text { elas estão sempre disponíveis na Internet (Men- } \\
\text { des Filho et al., 2001). }\end{array}$ \\
\hline
\end{tabular}




\author{
O papel do professor é o de coordenador do proces- \\ so, o responsável na "sala de aula virtual". Sua tarefa Os alunos que se inscreverem em cursos via rede \\ inicial é a de sensibilizar os alunos, motivá-los para a devem ter experiência prévia de navegação na \\ importância da matéria, mostrando entusiasmo, liga- Internet, ou o curso dever incluir uma unidade \\ ção da matéria com os interesses dos alunos, com a introdutória de modo a familiarizar o aluno com \\ totalidade da habilitação escolhida (Machado; Brin- esta tecnologia (Mendes Filho et al., 2001). \\ ghenti, 2000). \\ Quadro 2 - Posição do professor e aluno em relação às novas tecnologias disponíveis para o processo de Ensino-Aprendizagem \\ Fonte: Adaptado de Mendes Filho et al. (2001).
}

Observa-se no Quadro 2 que tanto o docente como o aluno devem se adaptar às inovações tecnológicas e utilizar-se dessas mudanças para melhorar seu desempenho acadêmico, além de desenvolver novas habilidades. Nesta perspectiva, observa-se que a aprendizagem por meio de ferramentas eletrônicas também pode contribuir para o crescimento dos níveis de conhecimento dos alunos, uma vez que, se programado para tanto, faz relembrar todos os conteúdos relacionados ao curso permitindo assim uma melhor fixação destes conteúdos e uma formação mais ampla, além de preparar o aluno para futuras experiências profissionais, o que é convergente as demandas do mercado de trabalho conforme destacado por Perrenoud (2002), Le Boterf (2003) e Soares, Araújo e Leal (2012).

\title{
2.4 O Sistema de Provas Eletrônicas - SPE
}

A utilização de recursos tecnológicos no ambiente de ensino é comumente denominada de tecnologias educativas ou tecnologias de ensino. As tecnologias educativas são utilizadas na educação como instrumentos de ensino e avaliação da aprendizagem (THOMPSON; SIMONSON; HARGRAVE, 1996; MIRANDA, 2007). De acordo com Miranda (2007), a introdução de novos meios tecnológicos no ambiente de ensino poderá produzir efeitos positivos na aprendizagem dos alunos. Isto ocorre, segundo Vygotsky (1994), por haver uma sintonia entre o desenvolvimento das funções psicológicas superiores dos indivíduos e os sistemas de tratamento e representação da informação.

Neste contexto, as tecnologias educativas servem a três funções nas instituições de ensino, sendo elas: funções de gestão educacional; funções de desenvolvimento educacional; e, recursos de aprendizagem, as quais influenciam o aluno e a sua aprendizagem (MIRANDA, 2007). A partir da utilização de tecnologias educativas, torna-se possível se identificar oportunidades de melhorias no ambiente de ensino, desenvolver ferramentas que estimulem o desenvolvimento educacional e a aprendizagem dos alunos (THOMPSON; SIMONSON; HARGRAVE, 1996).

Convergente a esta abordagem, no caso investigado nesta pesquisa, o Sistema de Provas Eletrônicas (SPE) é uma estratégia de ensino e de avaliação de aprendizagem, desenvolvida por uma instituição de ensino superior com o objetivo de avaliar o desempenho dos alunos durante sua formação superior em Administração ou Ciências Contábeis, revisando e mantendo presente no cotidiano dos alunos, conceitos ministrados em disciplinas já cursadas pelos discentes em semestres anteriores, o que possibilita a identificação de conteúdos que necessitam de maior reforço para a aprendizagem. O SPE atua como uma estratégia de ensino, sendo utilizado na instituição como uma tecnologia educativa, uma vez que revisa conceitos ministrados no curso, auxiliando na consolidação de conteúdos.

O SPE é uma modalidade de avaliação eletrônica, do tipo prova que complementa a avaliação das disciplinas dos respectivos cursos. Portanto, faz parte dos componentes avaliativos utilizados pela instituição para o estabelecimento da nota final dos alunos em cada disciplina. É uma avaliação compulsória, bimestral, porém, com um peso menor na composição da média 
final dos alunos em cada disciplina. Esta avaliação abrange questões de todas as disciplinas já cursadas pelos alunos em semestres anteriores.

O Sistema de Provas Eletrônicas foi estruturado em um banco de dados eletrônico, com uma interface amigável, similar a uma avaliação impressa, aonde o aluno responde a uma avaliação eletrônica individual (prova), composta por 40 questões de múltipla escolha, selecionadas aleatoriamente pelo sistema a partir do conjunto de disciplinas já cursadas pelos alunos. Desta forma a avaliação realizada a partir do SPE abrange o conteúdo de diferentes disciplinas.

Neste sistema foram cadastradas pela IES as matrizes curriculares dos cursos de graduação em Administração e Ciências Contábeis e, a partir deste cadastro, foram inseridas questões relacionadas a cada disciplina do curso, sendo estas classificadas em relação ao conteúdo a que se refere dentro de cada disciplina e o respectivo bimestre letivo, o que além de possibilitar a geração automática de avaliações, permite, posteriormente, a obtenção de informações relacionadas ao número de acertos ou erros por conteúdo, questão ou disciplina. Da mesma forma, os alunos matriculados nestes cursos são cadastrados neste sistema, aonde o registro das disciplinas cursadas e em curso delimitam as questões que poderão compor cada avaliação realizada por determinado aluno.

Uma justificativa para a criação e utilização de tais sistemas no ambiente de ensino, está relacionada à necessidade de preparação dos alunos para a realização de avaliações como o Exame Nacional de Desempenho dos Estudantes (Enade) e, no caso dos egressos do curso de Ciências Contábeis, do Exame de Suficiência promovido pelo Conselho Federal de Contabilidade (CFC), requisito obrigatório para a obtenção do registro profissional, conforme estabelece a Lei n. 12.249/2010. Adicionalmente, busca-se a partir da utilização de tais recursos, proporcionar condições para que os alunos possam alcançar uma melhor formação, com conhecimentos multidisciplinares de temas relacionados a estes cursos, o que é convergente as recomendações da Resolução CNE/CES n. 10/2004 e Resolução CNE/CES n. 4/2005, que estabelecem, respectivamente, as diretrizes curriculares nacionais dos cursos de graduação em Ciências Contábeis e Administração, e as demandas do mercado.

O Enade é um dos procedimentos de avaliação do Sistema Nacional de Avaliação da Educação Superior (Sinaes). É componente curricular obrigatório aos cursos de graduação, conforme determina a Lei n. 10.861/2004. É aplicado periodicamente aos estudantes de todos os cursos de graduação, durante o primeiro (ingressantes) e último (concluintes) ano do curso, tendo como objetivo o acompanhamento do processo de aprendizagem e do desempenho acadêmico dos estudantes em relação aos conteúdos programáticos previstos nas diretrizes curriculares do respectivo curso de graduação (INEP, 2014). Por sua vez, a Lei n. 12.249/2010, em seu artigo 12, estabelece que os profissionais da área contábil somente poderão exercer a profissão após a regular conclusão do curso de Bacharelado em Ciências Contábeis, reconhecido pelo Ministério da Educação; aprovação em Exame de Suficiência; e, registro no Conselho Regional de Contabilidade a que estiverem sujeitos (BRASIL, 2010).

Em ambos os casos, as avaliações do SPE abrangem questões relacionadas a todo o conteúdo ministrado nestes cursos, o que é convergente as avaliações do Enade e do CFC. Assim sendo, o sistema de provas eletrônicas oportuniza ao aluno, ao longo do curso, a revisão de conteúdos ministrados em disciplinas já cursados, mantendo-os presentes no seu cotidiano e possibilitando uma nova oportunidade para a absorção destes conteúdos, o que auxiliará na consolidação do mesmo e na aprendizagem.

Diante do exposto, espera-se que a partir da utilização de tais sistemas torne-se possível melhorar o desempenho dos acadêmicos destes cursos. Logo, torna-se oportuno identificar quais são as contribuições de um Sistema de Provas Eletrônicas (SPE) nos processos de ensino e 
UTILIZAÇÃO DE UM SISTEMA DE PROVAS ELETRÔNICAS (SPE) COMO ESTRATÉGIA DE ENSINO E AVALIAÇÃ̃O DE APRENDIZAGEM: UM ESTUDO DE CASO EM UMA INSTITUIÇÃO DE ENSINO SUPERIOR (IES)

avaliação da aprendizagem dos acadêmicos dos cursos de graduação presenciais em Administração e Ciências Contábeis de uma instituição de ensino superior, bem como qual a evolução do desempenho dos alunos nestas avaliações, motivações pelas quais se realiza este estudo.

\section{MÉTODOS E PROCEDIMENTOS DA PESQUISA}

A metodologia utilizada na pesquisa é caracterizada como um estudo de caso, de natureza exploratória e descritiva, com abordagem qualitativa e quantitativa dos dados. De acordo com Vergara (1998, p. 47), o estudo de caso é um método de pesquisa que constitui um "estudo circunscrito a uma ou poucas unidades, entendidas como uma pessoa, uma família, um produto, uma empresa, um órgão público, uma comunidade ou mesmo um país". O pesquisador não tem controle sobre os eventos e variáveis, buscando aprender a totalidade de uma situação e, criticamente, descrever, compreender e interpretar a complexidade de um caso concreto (MARTINS; THEÓPHILO, 2007, p. 61). A seleção do caso investigado é realizada de maneira intencional, sendo alcançada por conveniência.

Em relação à investigação exploratória, Gil (1999, p. 43) destaca que esta "é realizada especialmente quando o tema escolhido é pouco explorado e torna-se difícil sobre ele formular hipóteses precisas e operacionalizáveis". No que se refere à investigação descritiva, Vergara (1998, p. 45) explica que a pesquisa descritiva "expõe características de determinada população ou de determinado fenômeno. Pode também estabelecer correlações entre variáveis e definir sua natureza". Assim, a pesquisa é caracteriza como exploratória, pois busca fornecer evidências sobre a influência de um sistema de provas eletrônicas (SPE) nos processos de ensino e aprendizagem de alunos dos cursos de graduação presenciais em Administração e Ciências Contábeis de uma IES. Também pode ser caracterizada como descritiva, uma vez que descreve as características deste sistema implementado por uma instituição de ensino superior como uma estratégia de ensino e avaliação da aprendizagem dos alunos destes cursos. Da mesma forma, descreve uma análise da evolução do desempenho dos alunos nesta avaliação, bem como as percepções de docentes da IES sobre as contribuições do SPE nos processos de ensino e avaliação da aprendizagem.

Assim, inicialmente procurou-se identificar como está estruturado o sistema de provas eletrônicas na instituição pesquisada. Neste momento foram realizadas duas visitas in loco na instituição e entrevistas com os coordenadores dos cursos de Administração e Ciências Contábeis da IES. A seguir, procurou-se investigar os alunos destes cursos que realizaram estas avaliações durante o ano de 2010.

De posse destas informações, para que fosse possível inferir sobre a evolução do desempenho acadêmico dos alunos que participaram das avaliações do SPE, selecionou-se uma amostra intencional, ou seja, não probabilística, alcançada por acessibilidade, de 250 (duzentos e cinquenta) alunos dos cursos de graduação presencial em Administração (125) e Ciências Contábeis (125), que participaram regularmente das avaliações do SPE realizadas neste período. Segundo Colauto e Beuren (2008, p. 126), na amostra intencional o pesquisador seleciona a mostra com base em informações que estão disponíveis, e que a população possa ser considerada representativa.

Selecionada a amostra da pesquisa, na sequência, procurou-se investigar o número de acertos destes alunos em cada uma das avaliações do SPE realizadas neste período, bem como o desempenho nas demais avaliações bimestrais (provas) das disciplinas por eles cursadas no mesmo período. A última etapa da coleta de dados foi realizada a partir de entrevistas com os coordenadores de curso e dez docentes dos cursos de graduação presenciais em Administração e Ciências Contábeis, que atuam em ambos os cursos e possuem carga horária igual ou superior a 20 horas em sala de aula, aonde se procurou identificar as potenciais contribuições nos processos de ensino e avaliação da aprendizagem, obtidas a partir da utilização de um Sistema de Provas Eletrônicas (SPE). 
Desta forma, os processos de coleta de dados englobaram a pesquisa documental e a realização de entrevistas semiestruturadas com docentes (10) e coordenadores de curso (02).

$\mathrm{Na}$ etapa seguinte procedeu-se a tabulação e análise dos dados coletados na pesquisa. Os dados coletados foram tabulados no software Excel, e posteriormente analisados em duas etapas. A primeira etapa da análise dos dados foi realizada por meio da abordagem quantitativa e compreendeu a análise estatística descritiva de: média, mediana, moda, desvio-padrão, coeficiente de variação, assimetria, mínima e máxima do desempenho dos acadêmicos nas avaliações do SPE e das provas bimestrais. De acordo com Richardson (1999, p. 70), a abordagem quantitativa caracteriza-se pelo emprego de quantificação tanto nas modalidades de coleta de informações, quanto no tratamento delas por meio de técnicas estatísticas.

Tendo em vista as evidências encontradas em estudos anteriores, as quais sugerem que a utilização de recursos tecnológicos pode influenciar o desempenho, bem como os níveis de aprendizagem dos alunos (JONASSEN; MAYES; MCALEESE, 1993; JONASSEN, 1994; JONASSEN; CARR; YUEH, 1998; BERNSTEIN, 2001; HILLS; TEDFORD, 2003; VARIS, 2007; BEAK; JUNG; KIM, 2008; LONN; TEASLEY, 2009), estabeleceram-se as seguintes hipóteses de pesquisa, a serem testadas neste estudo:

- Hipótese nula (H0): Não existem diferenças estatisticamente significativas no desempenho dos alunos nas avaliações do SPE.

- Hipótese alternativa (H1): Existem diferenças estatisticamente significativas no desempenho dos alunos nas avaliações do SPE.

O teste de hipóteses utilizado no estudo é o teste de comparação de médias pela análise da variância (ANOVA a um fator). De acordo com Hair et al. (1998), a análise da variância é um método utilizado para determinar se as médias entre dois ou mais grupos ou populações são iguais. Assim, caso os resultados do teste realizado apresentarem significância estatística, a hipótese nula não poderá ser aceita, uma vez que as médias dos grupos investigados não são iguais.

A segunda etapa da análise dos dados foi realizada por meio da abordagem qualitativa. Nesta etapa da pesquisa procurou-se analisar o conteúdo das entrevistas realizadas com os coordenadores de cursos e os docentes participantes da pesquisa, a fim de se identificar quais as contribuições de um Sistema de Provas Eletrônicas (SPE) nos processos de ensino e avaliação da aprendizagem. De acordo com Richardson (1999, p. 39), os estudos que empregam uma metodologia qualitativa podem descrever a complexidade de determinado problema, analisar a interação de certas variáveis, compreender e classificar processos dinâmicos vividos por grupos sociais, contribuir no processo de mudança de determinado grupo e possibilitar, em maior nível de profundidade, o entendimento das particularidades do comportamento dos indivíduos. Os resultados do estudo de caso realizado são apresentados a seguir.

\section{APRESENTAÇÃO E ANÁLISE DOS RESULTADOS DA PES- QUISA}

\subsection{A Faculdade Motivação e o Sistema de Provas Eletrônicas (SPE)}

A organização pesquisada, denominada neste estudo com o nome fictício de Faculdade Motivação, é uma instituição privada de ensino superior que está localizada na Região Sul do Brasil. A IES em estudo iniciou suas atividades no ano de 2004, com dois cursos de graduação presenciais: Administração e Ciências Contábeis. Os cursos pesquisados são estruturados em oito semestres letivos, com carga horária total de 3.000 horas cada, abrangendo em sua proposta pedagógica disciplinas de formação geral e disciplinas de formação específica. 
UTILIZAÇÃO DE UM SISTEMA DE PROVAS ELETRÔNICAS (SPE) COMO ESTRATÉGIA DE ENSINO E AVALIAÇÃ̃O DE APRENDIZAGEM: UM ESTUDO DE CASO EM UMA INSTITUIÇÃO DE ENSINO SUPERIOR (IES)

Buscando aprimorar suas estratégias de ensino e avaliação de aprendizagem para a maximização do aprendizado acadêmico, a Faculdade Motivação instituiu no ano de 2008 o Sistema de Provas Eletrônicas (SPE). O SPE é uma modalidade de avaliação eletrônica, do tipo prova desenvolvida pela IES, que complementa a avaliação das disciplinas dos respectivos cursos. Nestas avaliações realizadas, o aluno tem contato com questões relacionadas a todo o conteúdo já ministrado em disciplinas anteriores. O objetivo desta avaliação é manter os conceitos de disciplinas anteriores presentes no cotidiano dos alunos, bem como identificar conteúdos que necessitam de maior reforço.

Neste sentido, a instituição pesquisada aplica o SPE em avaliações bimestrais obrigatórias. Assim sendo, os alunos realizam duas avaliações complementares em cada semestre letivo, a qual, por meio de uma média aritmética simples, resultará na nota referente a esta avaliação. Esta nota é somada as demais avaliações das disciplinas, para compor a média final do acadêmico nas mesmas. O SPE na instituição pesquisada é composto por quarenta questões objetivas (em cada avaliação), abrangendo os conteúdos já ministrados nas mesmas. A Tabela 1 apresenta uma síntese da forma de aplicação das avaliações do SPE na instituição.

Tabela 1 - Características das avaliações realizadas pelos acadêmicos da Faculdade Motivação no SPE

\begin{tabular}{c|c|c|c|c|c}
\hline $\begin{array}{c}\text { Especificação } \\
\text { das Avaliações }\end{array}$ & $\begin{array}{c}\text { Semestre letivo em } \\
\text { que se encontram } \\
\text { os acadêmicos }\end{array}$ & Conteúdo das avaliações & $\begin{array}{c}\text { Total de disciplinas } \\
\text { cursadas (ou em } \\
\text { curso) }\end{array}$ & $\begin{array}{c}\text { Qtde. de } \\
\text { questões por } \\
\text { disciplinas }\end{array}$ & $\begin{array}{c}\text { Total de questões } \\
\text { da avaliação }\end{array}$ \\
\hline 1a Aval. SPE & $1^{\circ}$ Semestre & Disciplinas do $1^{\circ}$ Bimestre & 5 & 8 & 40 \\
\hline 2a Aval. SPE & $1^{\circ}$ Semestre & Disciplinas do $1^{\circ}$ e $2^{\circ}$ Bimestre & 5 & 8 & 40 \\
\hline$\ldots$ & $\ldots$ & $\ldots$ & $\ldots$ & $\ldots$ & $\ldots$ \\
\hline 1a Aval. SPE & $3^{\circ}$ Semestre & Disciplinas $1^{\circ}$ e $2^{\circ}$ Semestre & 10 & 4 & 40 \\
\hline 2a Aval. SPE & $3^{\circ}$ Semestre & Disciplinas $1^{\circ}$ e $2^{\circ}$ Semestre & 10 & 4 & 40 \\
\hline$\ldots$ & $\ldots$ & $\ldots$ & $\ldots$ & $\ldots$ & $\ldots$ \\
\hline 1a Aval. SPE & $6^{\circ}$ Semestre & Disciplinas do $1^{\circ}$ ao $5^{\circ}$ Semestre & 25 & 1,6 & 40 \\
\hline 2a Aval. SPE & $6^{\circ}$ Semestre & Disciplinas do $1^{\circ}$ ao $5^{\circ}$ Semestre & 25 & 1,6 & 40 \\
\hline & & & & & \\
\hline 1a Aval. SPE & $8^{\circ}$ Semestre & Disciplinas do $1^{\circ}$ ao $7^{\circ}$ Semestre & 35 & 1,1 & 40 \\
\hline 2a Aval. SPE & $8^{\circ}$ Semestre & Disciplinas do $1^{\circ}$ ao $7^{\circ}$ Semestre & 35 & 1,1 & 40 \\
\hline
\end{tabular}

Fonte: Dados da Pesquisa.

Observa-se na Tabela 1 que, constantemente, o acadêmico acaba por revisar os conceitos das avaliações aplicadas em semestres anteriores. Logo, maximiza as chances de fixação dos mesmos. Nesta perspectiva, o SPE é alimentado constantemente pelos docentes das disciplinas, os quais (re)alimentam um banco de dados com questões ministradas durante o curso. A seleção das avaliações é realizada de forma automática e aleatória, considerando as disciplinas já cursadas pelos alunos. A fim de assegurar ao acadêmico a transparência nas avaliações que o mesmo está fazendo, as questões da referida prova são identificadas, inicialmente pelo nome da disciplina e, a seguir, pelo bimestre letivo que este conteúdo foi ministrado, como se observa na Figura 1.

Q01-CNT_INT_II_1 ${ }^{\circ} \_$BIM - A contagem periódica dos materiais existentes para efei-
to de comparação com os estoques registrados e contabilizados em controle da empresa, a fim
de se comprovar sua existência e exatidão, denomina-se:
( ) contabilização de estoques
( ) inventário físico
( ) conferencia de embarque
( ) inventário contábil
( ) custo ponderado móvel

Figura 1 - Exemplo de questão aplicada na modalidade de avaliação do SPE

Fonte: Dados da Pesquisa. 
A questão apresentada na Figura 1 é lida pelo aluno como a primeira questão da avaliação (Q01), e está relacionada à disciplina de Contabilidade Introdutória II (CNT_INT_II), conteúdo do primeiro bimestre letivo ( $\left.1^{\circ} \mathrm{BIM}\right)$. Esta informação está disponível em todas as quarenta questões de múltipla escolha, que compõe a referida prova. Ao final da realização da avaliação, o aluno recebe automaticamente o resultado de seu desempenho, indicando o número de acertos e o número de questões incorretas. O número de acertos determinará o resultado da avaliação, ou seja, a nota final do aluno na mesma.

Neste contexto, considerando-se as premissas para a implantação desta modalidade de avaliação na IES, torna-se necessário identificar se o desempenho dos acadêmicos está de fato sendo maximizado, como espera a instituição, bem como, qual a percepção dos docentes sobre esta modalidade de avaliação, o que se passa a apresentar na sequência.

\subsection{Análise do desempenho acadêmico dos participantes da pesquisa}

Para que fosse possível efetuar a análise do desempenho acadêmico da instituição nesta modalidade de avaliação, inicialmente torna-se necessário identificar a quantidade de alunos que realizaram a referida avaliação no período objeto de estudo, neste caso, no ano de 2010. Para esta análise, se considerou todas as edições realizadas no período. Ao todo, identificou-se a aplicação de quatro edições das referidas provas, sendo duas em cada semestre letivo. A Tabela 2 apresenta a síntese desta análise.

Tabela 2 - Quantidade de alunos que realizaram as avaliações do SPE no período em estudo

\begin{tabular}{cccccc}
\hline Curso & 2010_01 & 2010_02 & 2010_03 & 2010_04 & Total Geral \\
\hline Administração & 186 & 176 & 191 & 193 & $\mathbf{7 4 6}$ \\
Ciências Contábeis & 175 & 166 & 182 & 196 & $\mathbf{7 1 9}$ \\
\hline Totais & $\mathbf{3 6 1}$ & $\mathbf{3 4 2}$ & $\mathbf{3 7 3}$ & $\mathbf{3 8 9}$ & $\mathbf{1 4 6 5}$ \\
\hline Amostra Partic. SPE & $\mathbf{2 5 0}$ & $\mathbf{2 5 0}$ & $\mathbf{2 5 0}$ & $\mathbf{2 5 0}$ & 1000 \\
\hline \% Particip. SPE & $\mathbf{6 9 , 2 5 \%}$ & $\mathbf{7 3 , 1 0 \%}$ & $\mathbf{6 7 , 0 2 \%}$ & $\mathbf{6 4 , 2 7 \%}$ & $\mathbf{6 8 , 2 6 \%}$ \\
\hline
\end{tabular}

Fonte: Dados da Pesquisa.

Apesar de as avaliações bimestrais do SPE serem obrigatórias, nota-se que nem todos os alunos realizaram esta atividade no período investigado na pesquisa. Tendo em vista que o peso desta avaliação é pequeno na composição da nota final do aluno em cada disciplina (2 pontos), e, considerando-se que a nota final é resultante de uma média aritmética simples entre as avaliações realizadas na mesma (Provas + Trabalho + Avaliação SPE), é possível que o melhor desempenho dos alunos em outras avaliações influencie o seu desinteresse em realizar as duas avaliações bimestrais do SPE, o que explicaria tais resultados.

Observam-se na Tabela 2 que, no período analisado, foram realizadas 1.465 (um mil, quatrocentos e sessenta e cinco) avaliações em ambos os cursos, considerando todas as quatro edições (edições bimestrais). Em média, participaram de cada avaliação 366 (trezentos e sessenta e seis) alunos neste período. Para a análise proposta, optou-se por selecionar uma amostra que possibilite a análise do desempenho de alunos que realizaram todas as quatro edições desta avaliação, neste período. Neste sentido, selecionou-se uma amostra intencional, alcançada por acessibilidade, de duzentos e cinquenta participantes, sendo cento e vinte e cinco acadêmicos de cada curso, o que representa uma amostra geral de $68,26 \%$ das avaliações realizadas.

O objetivo desta análise é acompanhar o desempenho geral destes alunos nas quatro edições realizadas, buscando inferir sobre uma possível evolução do seu desempenho neste período. 
UTILIZAÇÃO DE UM SISTEMA DE PROVAS ELETRÔNICAS (SPE) COMO ESTRATÉGIA DE ENSINO E AVALIAÇÃO DE APRENDIZAGEM: UM ESTUDO DE CASO EM UMA INSTITUIÇÃO DE ENSINO SUPERIOR (IES)

Neste sentido, após a seleção da amostra, procurou-se identificar o desempenho destes acadêmicos em todas as avaliações do SPE e avaliações bimestrais por eles realizadas, coletando-se assim, as informações relacionadas ao número de acertos em questões destes alunos em cada edição. De posse destas informações, efetuou-se uma análise estatística descritiva, a fim de inferir sobre o desempenho geral dos acadêmicos analisados em cada avaliação. Os resultados da análise do desempenho dos acadêmicos nas quatro avaliações do SPE são apresentados na Tabela 3.

Tabela 3 - Estatística descritiva da análise do desempenho dos alunos analisados nas avaliações do SPE

\begin{tabular}{ccccccccc}
\hline Avaliação & Média & Mediana & Moda & $\begin{array}{c}\text { Desvio } \\
\text {-Padrão }\end{array}$ & $\begin{array}{c}\text { Coeficiente } \\
\text { de Variação }\end{array}$ & Assimetria & Mínimo & Máximo \\
\hline 2010_01 & $\mathbf{1 8 , 0 4}$ & 17 & 16 & 4,57 & 0,25 & 0,38 & 11 & 26 \\
2010_02 & 21,12 & 20 & 20 & 4,42 & 0,21 & 0,45 & 15 & 30 \\
2010_03 & 21,84 & 22 & 16 & 4,23 & 0,19 & 0,18 & 16 & 30 \\
2010_04 & $\mathbf{2 6 , 0 0}$ & 26 & $\mathbf{2 6}$ & $\mathbf{3 , 8 3}$ & $\mathbf{0 , 1 5}$ & $-0,16$ & 19 & 33 \\
\hline Geral & $\mathbf{2 1 , 7 5}$ & $\mathbf{2 2}$ & $\mathbf{1 6}$ & $\mathbf{5 , 1 2}$ & $\mathbf{0 , 2 4}$ & $\mathbf{0 , 0 5}$ & $\mathbf{1 1}$ & $\mathbf{3 3}$ \\
\hline
\end{tabular}

Fonte: Dados da Pesquisa.

Os resultados obtidos por meio da análise realizada na Tabela 3 evidenciam que, de maneira geral, o desempenho dos alunos é crescente. A média de acertos na primeira avaliação realizada pelos alunos em 2010 foi de 18,04 acertos. Já na última avaliação realizada pelos mesmos, no final do período, foi de 26 acertos. Estes dados são corroborados pela análise do coeficiente de variação, o qual também indica uma redução na dispersão do desempenho geral destes alunos.

Observa-se ainda na Tabela 3 que o número mínimo de acertos obtidos pelos alunos nestas avaliações também apresentou uma evolução no período analisado. Enquanto na primeira avaliação o menor número de acertos obtidos por este grupo de alunos analisados foi de onze acertos, na última edição, o mesmo subiu para dezenove. $O$ mesmo também ocorreu em relação ao número máximo de acertos, indicando uma ascendência também deste item. 0 Quadro 3 apresenta os resultados do teste de comparação de médias realizado a partir da análise da variância (ANOVA) a um fator.

ANOVA

\begin{tabular}{|c|c|c|c|c|c|}
\hline & $\begin{array}{c}\text { Soma dos Quadra- } \\
\text { dos }\end{array}$ & df & Quadrado Médio & F & Sig. \\
\hline Entre Grupos & 4028,950 & 3 & 1342,983 & 73,647 &, 000 \\
Nos grupos & 9044,800 & 496 & 18,235 & & \\
Total & 13073,750 & 499 & & & \\
\hline
\end{tabular}

Quadro 3-Resultados teste ANOVA

Fonte: Dados da Pesquisa.

Os resultados encontrados no Quadro 3 indicam a existência de diferenças entre as médias dos testes realizados pelos alunos observados na pesquisa, a um nível de significância estatística (0.000). Desta forma, a hipótese nula estabelecida na pesquisa é rejeitada, ou seja, as médias dos alunos nas avaliações do SPE realizadas neste período não são iguais.

De posse destas informações, na etapa seguinte, procurou-se verificar também mediante a análise estatística descritiva, o desempenho dos acadêmicos nas avaliações bimestrais das disciplinas em que estes se encontravam matriculados no mesmo período. Os resultados desta análise são apresentados na Tabela 4. 
Tabela 4 - Estatística descritiva da análise do desempenho dos alunos analisados nas avaliações bimestrais

\begin{tabular}{ccccccccc}
\hline Avaliação & Média & Mediana & Moda & $\begin{array}{c}\text { Desvio } \\
\text {-Padrão }\end{array}$ & $\begin{array}{c}\text { Coeficiente } \\
\text { de Variação }\end{array}$ & Assimetria & Mínimo & Máximo \\
\hline 2010_01 & 18,20 & 17 & 16 & 3,87 & 0,21 & 0,40 & 13 & 25 \\
2010_02 & 18,32 & 17 & 17 & 4,05 & 0,22 & 0,46 & 12 & 25 \\
2010_03 & 18,96 & 18 & 17 & 3,72 & 0,20 & 0,51 & 15 & 25 \\
2010_04 & 19,20 & 18 & 18 & 3,52 & 0,18 & 0,55 & 14 & 25 \\
\hline Geral & $\mathbf{1 8 , 6 7}$ & $\mathbf{1 7 , 5 0}$ & $\mathbf{1 7}$ & $\mathbf{3 , 7 6}$ & $\mathbf{0 , 2 0}$ & $\mathbf{0 , 4 2}$ & $\mathbf{1 2}$ & $\mathbf{2 5}$ \\
\hline
\end{tabular}

Fonte: Dados da Pesquisa.

Analisando-se os resultados encontrados na Tabela 4, pode-se verificar que o desempenho dos alunos nas avaliações bimestrais das disciplinas em curso também foi crescente, o que sugere uma melhoria no desempenho geral dos alunos. O coeficiente de variação observado nestas avaliações também é menor, o que indica um desempenho mais harmônico entre os alunos. Diferentemente das avaliações do SPE, as quais possuem 40 questões de conteúdos relacionados a diferentes disciplinas, as avaliações bimestrais são formadas a partir da elaboração de 25 questões de conteúdos específicos de cada disciplina em curso.

Portanto, mesmo que as evidências encontradas nesta etapa da pesquisa também indiquem um melhor desempenho dos alunos nas avaliações bimestrais das disciplinas, a comparação dos desempenhos em termos absolutos pode ser questionada. Mesmo que para a apuração dos resultados apresentados na Tabela 4 foram selecionados os mesmos alunos, questões relacionadas à tempestividade em que o conteúdo foi ministrado, o conteúdo abordado em ambas as avaliações que difere (mesmo que parcialmente), bem como o nível das questões, são fatores que também podem influenciar os resultados e a comparabilidade do desempenho dos acadêmicos. Logo, os resultados encontrados nesta etapa da pesquisa devem ser analisados, considerando-se tais ressalvas.

De maneira geral, verifica-se que o desempenho dos alunos nas avaliações do SPE, comparativamente às avaliações bimestrais, é um pouco inferior, porém crescente, o que indica uma melhoria contínua no desempenho geral dos alunos. Isto possivelmente está relacionado ao maior nível de dificuldade das avaliações do SPE, uma vez que ela retoma conteúdos de todas as disciplinas anteriores que o aluno já cursou ao longo do curso.

Como esta avaliação contempla um número maior de questões (40), torna-se possível a elaboração de uma avaliação mais abrangente, em termos de conteúdo, reforçando questões já vistas em atividades passadas (avaliação multidisciplinar). Em contrapartida, nas avaliações bimestrais, os conteúdos avaliados são ministrados concomitantemente nas disciplinas, de forma que estes se encontram mais recentes na memória dos alunos.

Neste contexto, pode-se verificar que, de maneira geral, os alunos estão obtendo um melhor desempenho nestas avaliações, o que pode estar relacionado com a absorção de conhecimento, e, por consequência, no melhor aprendizado dos acadêmicos. A utilização de um sistema de provas eletrônicas pela instituição permitiu aos docentes avaliar o desempenho dos alunos, identificando áreas de melhoria, ou seja, conteúdos que necessitam de reforço. Da mesma forma, a aplicação de tais avaliações induz o aluno a revisar constantemente conceitos relacionados às disciplinas passadas, o que contribui para a fixação dos conteúdos. Estes achados são convergentes as observações destacadas por Thompson, Simonson e Hargrave (1996) e Miranda (2007), no que se refere às funções das tecnologias educativas no ambiente de ensino, capazes de influenciar o aluno e a sua aprendizagem.

Tais ações também são convergentes à abordagem proposta pela Teoria Sociointeracionista de Vygotsky. Além de ser uma estratégia de ensino e avaliação de aprendizagem, o SPE oportuniza um 
momento particular de autoavaliação ao aluno. A autoavaliação permite ao participante refletir sobre o próprio processo de aprendizagem, fazendo um diagnóstico do seu desempenho (FERNANDES, 2008). As interações dos processos de ensino, autoavaliação e avaliação de aprendizagem contribuem para a formação dos processos de aprendizagem dos alunos. O SPE reforça e estimula o aprendizado. As questões discutidas em sala de aula, aplicadas em outras avaliações e constantemente revisadas, estimulam o desenvolvimento da Zona de Desenvolvimento Proximal (ZDP).

Os achados da pesquisa são convergentes ao de estudos anteriores, que demonstram a influência positiva dos recursos tecnológicos nos processos de ensino-aprendizagem (JONASSEN, 1994; JONASSEN; CARR; YUEH, 1998; BERNSTEIN, 2001; HILLS; TEDFORD, 2003; VARIS, 2007; BEAK; JUNG; KIM, 2008; LONN; TEASLEY, 2009). Jonassen, Mayes e Mcaleese (1994) e Jonassen, Carr e Yueh (1998) encontraram evidências sugerindo que, quando utilizadas de maneira adequada, as tecnologias educativas suportam de forma mais efetiva a construção de conhecimento no ensino superior e a promoção de aprendizagens relevantes. Ao promover uma reflexão sobre práticas pedagógicas e sua influência na geração de conhecimentos na educação, Bernstein (2001) infere que as tecnologias da informação são recursos capazes de influenciar a aprendizagem dos alunos. Neste sentido, Lonn e Teasley (2009), ao investigarem o uso e benefícios percebidos por docentes e alunos a partir da utilização de sistemas de gestão de aprendizagem, como um instrumento de apoio ao ensino tradicional em sala de aula, concluíram que professores e alunos valorizam o ensino a partir de ferramentas tecnológicas de aprendizagem.

Portanto, observa-se que o sistema de provas eletrônicas utilizado pela instituição como uma estratégia de ensino e avaliação de aprendizagem, atua como um facilitador do processo de aprendizagem, uma vez que auxilia docentes na fixação de conteúdos, bem como na identificação de conteúdos com maior necessidade de reforço, o que pode ser trabalhado pela instituição, professores e alunos, a fim de se obter um aprendizado também destes conteúdos.

\subsection{Percepções dos docentes sobre o Sistema de Provas Eletrônicas}

Nesta etapa da pesquisa, procurou-se identificar junto aos coordenadores dos cursos de Administração e Ciências Contábeis e dez docentes que atuam em ambos os cursos com carga horária mínima de 20 horas semanais em sala de aula, a percepção destes em relação à implementação do sistema de provas eletrônicas na instituição e os benefícios que podem ser obtidos nos processos de ensino e avaliação da aprendizagem, a partir da utilização deste recurso. 0 Quadro 4 apresenta algumas observações relacionadas aos principais benefícios obtidos com a implantação do SPE, segundo a percepção de docentes.

Docente A: "[...] o SPE proporciona aos acadêmicos a consolidação de diversos conceitos que desenvolvemos em sala de aula [...]".

Docente B: “[...] em minha opinião, o SPE contribui na formação dos alunos e maximiza o aprendizado dos alunos, pela replicação de questões relacionadas a disciplinas já vistas anteriormente, favorecendo a interdisciplinaridade [...]".

Docente D: "[...] os egressos de nossa instituição deverão desenvolver uma formação multidisciplinar mais sólida. Com certeza isto se deve, ao menos em partes, a preparação pelo SPE [...]".

Docente F: "[...] após a implantação do SPE, percebe-se que os principais conceitos de outras disciplinas estão mais presentes no dia a dia dos alunos, fazendo com que a aula flua mais [...]".

Docente I: "[...] os alunos compraram a ideia... só por isto o SPE deu certo. Ganhamos em qualidade e aprendizagem" [...].

Quadro 4 - Benefícios obtidos a partir da implementação do SPE

Fonte: Dados da Pesquisa. 
Analisando-se os resultados evidenciados no Quadro 4, pode-se perceber que os benefícios destacados pelos docentes indicam que esta modalidade de avaliação favorece o aprendizado acadêmico. Evidentemente que isto não deve estar relacionado só a este fator. No entanto, o mesmo contribuiu de alguma forma, para a melhoria dos níveis de aprendizagem na instituição. Observa-se a partir dos relatos coletados, que os alunos da instituição teriam "comprado à ideia" deste sistema, o que favorece sua implementação e a posterior utilização.

Nesta perspectiva, ao aceitarem a adoção desta tecnologia no ambiente de ensino, entende-se que os alunos também tendem a perceber o SPE como uma oportunidade de revisar conceitos e fixar conteúdos. Da mesma forma, permite a identificação de oportunidades de melhorias, a partir das quais, instituição, professores e alunos poderão atuar com a finalidade de fixar os conteúdos que se encontram em processo de absorção. De acordo com o Coordenador do Curso de Administração da instituição pesquisada:

\begin{abstract}
A avaliação do Sistema de Provas Eletrônicas permite identificar as disciplinas que os alunos possuem maior dificuldade. Também é possível se identificar os conteúdos e as questões que apresentam o maior número de erros ou acertos. Isto permite o Professor enfatizar mais determinado conteúdo em sala de aula. No SPE também é possível classificar as questões das avaliações, por grau de dificuldade, por exemplo, questões de nível básico, médio e avançado. Assim, diferentes provas podem ser elaboradas, considerando-se os diferentes níveis de dificuldade das questões (Coord. Curso de ADM).
\end{abstract}

Estudos anteriores têm sugerido, a partir da utilização de sistemas de gestão de aprendizagem, que alunos têm alcançado fortes benefícios de aprendizagem (HANSON; ROBSON, 2004; YOHON; ZIMMERMAN; KEELER, 2004; PARKER; BIANCHI; CHEAH, 2008), razão pela qual se tem observado uma maior valorização por parte de professores e alunos, na inserção de recursos tecnológicos no ambiente de ensino (LONN; TEASLEY, 2009). Neste sentido, o uso da TI, somado às estratégias de ensino, pode elevar os índices de aprendizagem dos acadêmicos (JONASSEN; MAYES; MCALEESE, 1993; JONASSEN, 1994; JONASSEN; CARR; YUEH, 1998; BERNSTEIN, 2001; HANSON; ROBSON, 2004; YOHON; ZIMMERMAN; KEELER, 2004; PARKER; BIANCHI; CHEAH, 2008; LONN; TEASLEY, 2009). Logo, é possível pressupor que a utilização de um sistema de provas eletrônicas pode contribuir na maximização do aprendizado acadêmico.

Por outro lado, um dos principais desafios enfrentados a partir da implantação desta modalidade de avaliação, segundo os docentes entrevistados, é a revisão periódica do banco de dados de questões relacionadas às disciplinas, tarefa importante para a manutenção do mesmo. Por meio de questões atualizadas, torna-se possível estimular a aprendizagem dos alunos. No entanto, caso ocorra à falta de manutenção destas questões, pode-se incorrer num falso aprendizado, a partir de interpretações equivocadas decorrentes do aprendizado obtido a partir de questões desatualizadas, que não condizem mais com aquela realidade.

Isto pode estar relacionado principalmente, com questões de disciplinas que exploram o contexto econômico-social, bem como, questões relacionadas à aplicação do direito. A pesar deste desafio, de maneira geral, pode-se perceber que esta modalidade de avaliação encontra-se consolidada na instituição, uma vez que já está sendo desenvolvida a mais de dois anos na mesma e está indicando a melhoria do desempenho acadêmico, conforme os resultados e relatos identificados nesta pesquisa.

\title{
5 CONSIDERAÇÕES FINAIS
}

Este estudo teve por objetivo identificar as contribuições de um Sistema de Provas Eletrônicas (SPE) nos processos de ensino e avaliação da aprendizagem dos acadêmicos dos Cursos 
UTILIZAÇÃO DE UM SISTEMA DE PROVAS ELETRÔNICAS (SPE) COMO ESTRATÉGIA DE ENSINO E AVALIAÇÃ̃O DE APRENDIZAGEM: UM ESTUDO DE CASO EM UMA INSTITUIÇÃO DE ENSINO SUPERIOR (IES)

de Graduação presenciais em Administração e Ciências Contábeis de uma instituição de ensino superior. Mais especificamente, procurou-se verificar se esta modalidade de avaliação pode contribuir com as Instituições de Ensino Superior (IES) na maximização da relação ensino-aprendizagem. Para tanto, desenvolveu-se um estudo de caso, de natureza descritiva, com abordagem qualitativa e quantitativa dos dados.

Inicialmente procurou-se identificar a forma de utilização do SPE na instituição pesquisada. Observou-se que o SPE é uma modalidade de avaliação eletrônica, do tipo prova, desenvolvida pela instituição com o propósito de revisar e fixar conteúdos de disciplinas já cursadas em semestres anteriores, bem como identificar conteúdos que necessitam de maior reforço para absorção. O SPE complementa a avaliação das disciplinas dos respectivos cursos, abrangendo questões de todas as disciplinas já cursadas pelos alunos. No período investigado foram aplicadas quatro avaliações desta modalidade, sendo duas no primeiro semestre letivo de 2010 e duas no segundo. Em média, participaram de cada avaliação 366 (trezentos e sessenta e seis) alunos. Considerando-se todo o período observado na pesquisa, identificou-se a realização de 1.465 avaliações do SPE em ambos os cursos.

A seguir, procurou-se analisar a evolução do desempenho acadêmico de alunos dos cursos de Administração e Ciências Contábeis nas avaliações do SPE e avaliações bimestrais (provas) das disciplinas. Para tanto, selecionou-se uma amostra intencional, alcançada por acessibilidade, de 250 (duzentos e cinquenta) alunos que participaram regularmente das quatro avaliações do SPE realizadas no ano de 2010, sendo 125 (cento e vinte e cinco) alunos de cada curso. Ao todo, estes 250 alunos investigados na pesquisa realizaram 1.000 avaliações do sistema de provas eletrônicas.

Os resultados encontrados indicam que o desempenho dos alunos nas avaliações do SPE foi crescente, sendo que a média de acertos na primeira avaliação analisada foi de 18,04 acertos, e, a média geral na última avaliação, de 26 acertos de um total de 40 acertos possíveis. Esses resultados são corroborados pela análise do coeficiente de variação, que indicou uma redução na dispersão do desempenho geral destes alunos, o que representa um melhor desempenho de todo o grupo analisado. $O$ teste de hipóteses realizado na pesquisa evidencia a existência de diferenças de médias no desempenho dos alunos nas quatro edições do SPE. Desta forma, é aceita a hipótese alternativa $(\mathrm{H} 1)$ de que existem diferenças estatisticamente significativas no desempenho dos alunos nas avaliações do SPE. Resultados similares foram observados nas avaliações bimestrais, em que o desempenho dos alunos também foi crescente e o coeficiente de variação menor, o que indica maior harmonia no desempenho geral dos alunos.

Os achados da pesquisa são convergentes aos achados de estudos anteriores, que indicam uma influência positiva da utilização dos recursos tecnológicos nos processos de ensino-aprendizagem (JONASSEN; MAYES; MCALEESE, 1993; JONASSEN, 1994; JONASSEN; CARR; YUEH, 1998; BERNSTEIN, 2001; HILLS; TEDFORD, 2003; HANSON; ROBSON, 2004; YOHON; ZIMMERMAN; KEELER, 2004; VARIS, 2007; BEAK; JUNG; KIM, 2008; PARKER; BIANCHI; CHEAH, 2008; LONN; TEASLEY, 2009). Observa-se que o uso de tais recursos, se utilizados de maneira adequada, podem facilitar a aprendizagem dos alunos, uma vez que atuam como uma estratégia de ensino ao revisarem conceitos e conteúdos ministrados em sala de aula; promovem uma auto avaliação do aluno em relação a seus conhecimentos já consolidados; e, permite a identificação de conteúdos que requerem reforço, sobre os quais instituição, professores e alunos poderão atuar.

Em relação à percepção dos docentes dos cursos pesquisados sobre a influência do Sistema de Provas Eletrônicas no ensino e aprendizado dos acadêmicos, pôde-se verificar que o SPE está contribuindo para a melhoria dos níveis de aprendizagem dos alunos. As principais 
contribuições de um Sistema de Provas Eletrônicas (SPE) nos processos de ensino e avaliação da aprendizagem, destacadas pelos docentes participantes da pesquisa, estão relacionadas à identificação de áreas de melhoria, o reforço de conteúdos ministrados durante o curso, a consolidação de conceitos básicos, a ampliação dos conhecimentos gerais (aprendizagem multidisciplinar), maior qualidade de ensino e melhores níveis de aprendizagem.

Desta forma, a partir dos resultados encontrados neste estudo, pode-se verificar que os alunos da instituição estão alcançando um melhor aprendizado de todo o conteúdo ministrado no curso, o que ao menos em partes pode ser atribuído à utilização deste recurso. Conclui-se que o SPE pode ser uma eficiente estratégia de ensino e avaliação de aprendizagem a ser utilizada por instituições de ensino superior. Além de ser uma estratégia de ensino que estimula a fixação de conteúdos e proporciona uma avaliação dos conhecimentos gerais dos alunos desenvolvidos durante o curso, o SPE possibilita a identificação de disciplinas e conteúdos em que os alunos possuem maior dificuldade, o que posteriormente pode ser trabalhado pela instituição para meIhorar os níveis de aprendizagem dos alunos.

O desenvolvimento desta modalidade de avaliação possibilita ainda a identificação das questões que apresentam maiores números de erros ou acertos. Logo, torna-se possível o desenvolvimento de ações com vistas a fortalecer as áreas que demandam maior esforço para o aprendizado dos acadêmicos. Tais ações podem contribuir para a absorção dos conteúdos que se encontram em processo de amadurecimento, conforme destacado por Vygotsky (1978), o que, por consequência, resultará em melhoria dos níveis de aprendizagem dos alunos.

Evidentemente que o estudo apresenta algumas limitações, as quais não permitem a generalização dos resultados desta pesquisa. Uma das limitações do trabalho refere-se ao fato de que nem todos os docentes da IES pesquisada foram entrevistados. Outra limitação refere-se ao fato de se excluir da amostra pesquisada aqueles alunos que não realizaram todas as avaliações do SPE no período objeto de estudo.

No entanto, os achados da pesquisa fornecem evidências que estimulam a realização de novos estudos, o que pode contribuir para o desenvolvimento de uma linha de pesquisa sobre esta temática. Novas investigações devem ser realizadas para que seja possível afirmar com certeza que o SPE pode influenciar efetivamente os níveis de aprendizagem dos alunos. Tendo em vista os resultados de estudos anteriores, que sugerem uma série de benefícios que podem ser obtidos a partir da utilização de recursos tecnológicos nos processos de ensino e aprendizagem, torna-se oportuna a realização de novas pesquisas a fim de se confirmar ou refutar os achados deste estudo.

A observação de que as notas dos alunos apresentaram crescimento pode não ter relação direta com o SPE. Nesta perspectiva, experimentos podem ser desenvolvidos para que se possa checar esta nova hipótese de pesquisa. Desta forma, a influência de variáveis como o grau de dificuldade das questões e a demografia dos respondentes pode ser investigada a partir da utilização de um grupo de controle. Nestes casos, um grupo de alunos não fariam as avaliações no formato eletrônico.

Adicionalmente, sugere-se ainda a replicação desta pesquisa a partir de um espaço temporal maior, a fim de se identificar, em um recorte transversal mais amplo, se o desempenho acadêmico destes alunos está se mantendo constante ao longo do curso, mediante a inclusão de novas disciplinas nas avaliações. Também se sugere a análise da relação entre os resultados dos acadêmicos nestas avaliações e o desempenho destes alunos na avaliação do Enade, uma vez que esta avaliação também inclui conteúdos estabelecidos nas diretrizes curriculares dos cursos que contemplam toda a formação dos alunos.

A realização de investigações a partir da inclusão de uma população maior ou mediante a investigação de análise comparativas, podem auxiliar gestores de cursos e da instituição em processos 
de identificação de potencialidades e fraquezas dos respectivos cursos. Por fim, outros estudos também podem ser realizados diretamente com os alunos que realizam as avaliações do SPE, mediante a abordagem qualitativa ou quantitativa dos dados, consolidando-se esta temática de investigação.

\section{REFERÊNCIAS}

ANASTASIOU, L. G. C.; ALVES, L. P. (Orgs.). Estratégias de ensinagem. Processos de ensinagem na universidade. Pressupostos para as estratégias de trabalho em aula. 3. ed. Joinville: Univille, 2004. p. 67-100.

ANDERSSON, S. B. Newly qualified teachers' learning related to their use of information and communication technology: a Swedish perspective. British Journal of Educatioanl Technology, v. 37, p. 665-682, 2006.

ANJOS, G. C. B.; CASTRO, W. A. M. A utilização da internet pelos cursos de graduação em Administração: um estudo nos sites das IFES brasileiras. In: IV SEGeT - Simpósio de Excelência em Gestão e Tecnologia, 2007, Rezende/RJ. Anais... Rezende: IV SEGeT, 2007. CD-ROM.

ARAúJO, A. M. P.; SANTANA, A. L. A.; RIBEIRO, E. M. S. Fatores que afetam o processo de ensino no curso de Ciências Contábeis: um estudo baseado na percepção dos professores. In: Congresso ANPCONT - Associação Nacional dos Programas de Pós-Graduação em Ciências Contábeis, 2009, São Paulo/SP. Anais... São Paulo: III ANPCONT, 2009. CD-ROM.

BARBOSA, R. M. Ambientes virtuais de aprendizagem. Porto Alegre: ARTMED, 2005.

BEAK, Y.; JUNG, J.; KIM, B. What makes teachers use technology in the classroom? Exploring the factors affecting facilitation of technology with a Korean sample. Computer \& Education, v. 50, p. 224-234, 2008.

BERNSTEIN, B. From pedagogies to knowledges. In: MORAIS, A.; NEVES, I.; DAVIES, B.; DANIELS, H. Towards a sociology of pedagogy. New York: Lang, 2001.
BRASIL. Lei n. 9.394/1996 - Estabelece as diretrizes e bases da educação nacional. Disponível em: <http://www.planalto.gov. br/ccivil_03/leis/19394.htm>. Acesso em: 10.05.2011.

BRASIL. Lei n. 10.861/2004 - Institui o Sistema Nacional de Avaliação da Educação Superior SINAES. Disponível em: <http://www.planalto. gov.br/ccivil_03/_ato2004-2006/2004/lei/ 110.861.htm>. Acesso em 05.03.2014.

BRASIL. Lei n. 12.249/2010 - Institui o Exame de Suficiência do Conselho Federal de Contabilidade como requisito obrigatório para o exercício profissional. Disponível em: <http://www.planalto.gov.br/ccivil_03/_ ato2007-2010/2010/lei/l12249.htm>. Acesso em 05.03.2014.

BRASIL. Resolução CNE/CES n. 10/2004 Diretrizes Curriculares Nacionais do Curso de Graduação em Ciências Contábeis. Disponível em: <http://portal.mec.gov.br/cne/arquivos/ pdf/rces10_04.pdf>. Acesso em 05.03.2014.

BRASIL. Resolução CNE/CES n. 4/2005 Diretrizes Curriculares Nacionais do Curso de Graduação em Administração. Disponível em: <http://portal.mec.gov.br/cne/arquivos/pdf/ rces004_05.pdf >. Acesso em 05.03.2014.

CARdoso, E. L.; PIMENTA, P.; PEREIRA, D. C. Adoção de Plataformas de e-Learning nas Instituições de Ensino Superior - modelo do processo. Revista Tékhne [online], n. 9, p. 173193, 2008.

CARVAlHO JR., P. M. Modelo de uso da tecnologia de informação no suporte ao processo de ensino-aprendizagem baseado em problemas no curso medico: desenvolvimento e avaliação. Tese (Doutorado em Engenharia Elétrica). 235 p. Faculdade de Engenharia Elétrica e de Computação, Universidade 
Estadual de Campinas, 2002.

CARVALHO JR., P. M. Modelo de uso da tecnologia de informação no suporte ao processo de ensino-aprendizagem baseado em problemas no curso médico: desenvolvimento e avaliação. Revista Interface - Comunicação, Saúde e Educação [online], v. 7, n. 12, p. 172172, 2003.

CHAIKLIN, S. The zone of proximal development in Vygotsky's analysis of learning and instruction. In: KOZULIN, A.; GINDIS, B.; AGEYEV, V. S.; MILLER, S. M. (Org.). Vygotsky's educational theory in cultural context. Cambridge University Press, 2003.

CLARK, R. E. Reconsidering Research on Learning from Media. Review of Educational Research, v. 53, n. 4, p. 445-459, 1983.

COLAUTO, R. D.; BEUREN, I. M. Coleta, análise e interpretação dos dados. In: BEUREN, I. M. (org). Como Elaborar Trabalhos Monográficos em Contabilidade. 3. ed. São Paulo: Atlas 2008.

DUNN, W. E.; LANTOLF, J. P. Vygotsky's zone of proximal development and Krashen's "i +1 ": Incommensurable constructs; incommensurable theories. Language Learning, v. 48, p. 411-442, 1998.

FACCI, M.; TESSARO, N.; LEAL, Z. R. G.; SILVA, V.; ROMA, C. Psicologia Histórico-Cultural e Avaliação Psicológica: o processo ensino aprendizagem em questão. Revista Semestral da Associação Brasileira de Psicologia Escolar e Educacional (ABRAPEE), v. 11, n. 2, p. 323338, Jul./Dez., 2007.

FAHY, P. J. Media characteristics and on-line learning technology. In: ANDERSON, T. T.; ELIOUMI, F. Theory and practice of on-line learning. Athabasca: Athabasca University, 2004.

FERNANDES, D. Para uma teoria da avaliação no domínio das aprendizagens. Estudos em Avaliação Educacional, v. 19, n. 41, set./dez., 2008.
GIL, A. C. Métodos e técnicas de pesquisa social. 5a ed. São Paulo: Atlas, 1999.

GOMES, R. C.; COSTA, R H.; NEVES, A. A.; SCHIMIGUEL, J.; SILVEIRA, I. F.; AMARAL, L. H. Teorias de aprendizagem: pré-concepções de alunos da área de exatas do ensino superior privado da cidade de São Paulo. Ciência \& Educação, v. 16, n. 3, p. 695-708, 2010.

HAIDT, R. C. C. Curso de didática geral. 7ạ ed. São Paulo: Ática, 2003.

HAIR, J. F.; ANDERSON, R. E.; TATHAM, R. L.; BLACK, W. C. Multivariate data analysis with readings. 5. ed. New Jersey: Prentice Hall, 1998.

HANSON, P.; ROBSON, R. Evaluating course management technology: a pilot study. Boulder, CO: EDUCAUSE Center for Applied Research. Research Bulletin, v. 2004, n. 24, p. 1-13, nov., 2004.

HILLS, G.; TEDFORD, D. The education of engineers: the uneasy relationship between engineering, science and technology. Global Journal of Engineering Education (UICEE), v. 7, p. 17-28, 2003.

HOCAYEN-DA-SILVA, A. J.; CASTRO, M.; MACIEL, C. O. Perfil profissional e práticas de docência nos cursos de administração: por onde andam as novas tecnologias do ensino superior? Revista de Administração Mackenzie (RAM), v. 9, n. 5, p. 155-178, 2008.

INEP, Instituto Nacional de Estudos e Pesquisas Educacionais Anísio Teixeira. Enade. Disponível em: <http://portal.inep.gov.br/enade>. Acesso em 05.03.2014.

JONASSEN, D.; MAYES, T.; MCALEESE, R. A manifesto for a construtivist approach to technology in higher education. In: MAYES, T.; JONASSEN, D.; DUFFI, T.; LOWYCK, J. (eds.). Designing Constructivist Learning Environments, Springer-Verlag: Heidelberg, p. 231-247, 1993. 
JONASSEN, D. Technology as cognitive tools: learners as designers. In: Instructional Technology Forum, 1994, Georgia. Anais... Georgia: ITFORUM, 1994. Disponível em: http://itforum.coe.uga.edu/paper1/paper1. html. Acesso em: 10 Set 2011.

JONASSEN, D.; CARR, C.; YUEH, H. Computers as mindtools for engaging learners in critical thinking. TechTrends, v. 43, p. 24-32, 1998.

KEARNS, G. S.; SABHERWAL, R. Strategic alignment between business and information technology: a knowledge-based view of behaviors, outcome, and consequenses. Journal of Management Information Systems, v. 23, n. 3, p. 129-162, 2006.

KILGORE, D. W. Understanding learning in social movements: A theory of collective learning. International Journal of Lifelong Education, v. 18, p. 191-202, p. 1999.

LANTOLF, J. P.; PAVLENKO, A. Sociocultural theory and second language acquisition. Annual Review of Applied Linguistics, v. 15, p. 108-124, 1995.

LEÃO, D. M. M. Paradigmas contemporâneos de educação: escola tradicional e escola construtivista. Cadernos de Pesquisa, n. 107, p. 187-206, jul., 1999.

LE BOTERF, G. Desenvolvendo a competência dos profissionais. 2a ed. Porto Alegre: Artmed Editora, 2002.

LEVY, P. A inteligência coletiva: por uma antropologia do ciberespaço. 2 a ed. São Paulo: Loyola, 1999.

LITWIN, E. Tecnologia educacional: Políticas, histórias e propostas. Porto Alegre: ArtMed, 2001.

LIU, L.; TIMOTHY, V.; GAO, Y. A review of approaches of resource-based empirical research in banking. The International Journal of Applied Economics and Finance, v. 4, n. 4, p. 230-241, Jun., 2010.
LONN, S.; TEASLEY, S. D. Saving time or innovating practice: investigating perceptions and uses of Learning Management Systems. Computers \& Education, v. 53, p. 686-694, 2009.

MIRANDA, G. L. Limites e possibilidades das TIC na educação. Sísifo Revista de Ciências da Educação, n. 3, p. 41-50, mai./ago., 2007.

MORAIS, N.; CABRITA, I. M. Ambientes virtuais de aprendizagem: comunicação (as)síncrona e interação no ensino superior. Revista de Ciências da Informação e da Comunicação do CETAC, Porto, n. 6, p. 158-179, jul., 2008.

MOROZINI, J. F.; CAMBRUZZI, D.; LONGO, L. Fatores que influenciam o processo de ensinoaprendizagem no curso de ciências contábeis do ponto de vista acadêmico. Revista Capital Científico do Setor de Ciências Sociais Aplicadas, v. 5, n. 1, Jan./Dez., 2007.

MAHDIZADEH, H.; BIEMANS, H.; MULDER, M. Determining factors of the use of e-learning environments by university teachers. Computers \& Education, v. 51, p. 142-154, 2008.

MARTINS, G. A.; THEÓPHILO, C. R. Metodologia da investigação científica para ciências sociais aplicadas. São Paulo: Editora Atlas, 2007.

MAZZIONI, S. As estratégias utilizadas no processo de ensino-aprendizagem: concepções de alunos e professores de Ciências Contábeis. Revista Eletrônica de Administração e Turismo, ReAT, Pelotas, v. 2, n. 2, p. 1-16, 2013.

MENDES FILHO, L. A. M.; ALLOUFA, J. M. L.; QUEIROZ, T. S.; ADESHOYE, I. A.; RAMOS, A. S. M. Inovações tecnológicas no ensino: contribuições teóricas. In: CONGRESSO BRASILEIRO DE ENSINO DE ENGENHARIA, 29. 2001, Porto Alegre. Anais... Porto Alegre: ABENGE - Associação Brasileira de Ensino de Engenharia, 2001. CD-ROM.

MORAN, J. M. Como utilizar a internet na educação. Revista Ciência da Informação, v. 
26, n. 2, p. 146-153, mai./ago., 1997.

O'BRIEN, J. A. Sistemas de informação e as decisões gerenciais na era da Internet. 9. ed. São Paulo: Saraiva, 2002.

PALLOFF, R.; PRAT, K. Building learning communities in cyberspace. San Francisco: Jossey-Bass, 1999.

PARKER, R.E.; BIANCHI, A.; CHEAH, T.Y. Perceptions of instructional technology: factors of influence and anticipated consequences. Educational Technology and Society, v. 11, n. 2, p. 274-293, 2008.

PERRENOUD, P. A prática reflexiva no ofício do professor: profissionalização e razão pedagógica. Porto Alegre: Artmed Editora, 2002.

PINTO, A. C. Memória, cognição e educação: Implicações mútuas. In: DETRY, B.; SIMAS, F. (Eds.). Educação, cognição e desenvolvimento: Textos de psicologia educacional para a formação de professores. Lisboa: Edinova, 2001.

PIRES, C. B.; OTT, E.; DAMACENA, C. A formação do contador e a demanda do mercado de trabalho na região metropolitana de Porto Alegre (RS). BASE - Revista de Administração e Contabilidade da Unisinos, São Leopoldo, v. 7, n. 4, out./dez. 2010.

RAMOS, A. S. M.; CARVALHO, M. L. A.; NASCIMENTO, T. C. Diferenças de gênero na intenção de uso de um ambiente virtual de aprendizagem: um estudo com professores de uma Universidade Federal. In: XXVI Simpósio de Gestão da Inovação Tecnológica, Vitória/ ES, 2010. Anais... Vitória: ANPAD, 2010. CD-ROM.

RICHARDSON, R. J. Pesquisa social: métodos e técnicas. 3. ed. São Paulo: Atlas, 1999.

SILVA, M. Educação on-line: teorias, práticas, legislação, formação corporativa. São Paulo: Loyola, 2003.
SOARES, M. A.; ARAÚJO, A. M. P.; LEAL, E. A. Evidências empíricas da aplicação do método Problem-Based Learning (PBL) na disciplina de Contabilidade Intermediária do Curso de Ciências Contábeis. In: COIMBRA, C. L. (Org.). Didática para o ensino nas áreas de Administração e Ciências Contábeis. São Paulo: Atlas, v. 1, p. 74-92, 2012.

SPOUSE, J. Scaffolding student learning in clinical practice. Nurse Education Today, v. 18, p. 259-266, 1998.

STACCIARINI, J M. R.; ESPERIDIÃO, E. Repensando Estratégias De Ensino No Processo De Aprendizagem. In: Revista Latinoamericana de Enfermagem, Ribeirão Preto, v. 7, n. 5, p. 59-66, dez./1999.

TAPPAN, M. B. Moral education in the zone of proximal development. Journal of Moral Education, v. 27, p. 141-160, 1998.

TEO, T.; LEE, C. B.; CHAl, C. S. Understanding pre-service teachers' computer attitudes: applying and extending the technology acceptance model. Journal of Computer Assisted Learning, v. 24, p. 128-143, 2007.

THOMPSON, A. D.; SIMONSON, M. R.; HARGRAVE, C. P. Educational Technology: A review of the research. 2 nd ed. Washington, $D$. C.: Association for Educational Communications and Technology (AECT), 1996.

TRINTA, R. R. A Zona de Desenvolvimento Proximal em contextos de ensinoaprendizagem de língua estrangeira: definição, diferentes interpretações, perspectivas de estudo. Revista Intercâmbio, São Paulo (LAEL/ PUC-SP), v. XX, p. 150-173, 2009.

VARIS, T. New technologies and innovation in higher education and regional development. Revista de Universidad y Sociedad del Conocimiento (RU\&SC), v. 4, n. 2, p. 16-24, 2007.

VERGARA, S. C. Projetos e Relatórios de Pesquisa em Administração. São Paulo: Atlas, 1998. 
VYGOTSKY, L. S. Learning and mental development at school age. In: SIMON, B.; SIMON, J. Educational psychology in the USSR. London: Routledge \& Kegan Paul, 1963.

VYGOTSKY, L. S. Play and its role in the mental development of the child. Soviet Psychology, v. 5, n. 3, p. 1-6, 1967.

VYGOTSKY, L. S. Apprendimento e sviluppo nell'et à prescolare. In: Lo sviluppo psichico del bambino. Roma: Riuniti, 1973.

VYGOTSKY, L. S. Interaction between learning and development. In: COLE, M.; JOHNSTEINER, V.; SCRIBNER, S.; SOUBERMAN, E. Mind in society: The development of higher psychological processes. Cambridge University Press, 1978.

VYGOTSKY, L. S. Obras escogidas II. Madrid: Centro de Publicaciones del M.E.C. y Visor Distribuciones. 1993.

VYGOTSKY, L. S. A formação social da mente. $O$ desenvolvimento dos processos psicológicos superiores. 5a ed. São Paulo: Martins Fontes, 1994.

YOHON, T.; ZIMMERMAN, D.; KEELER, L. An exploratory study of adoption of course management software and accompanying instructional changes by faculty in the liberal arts and sciences. Electronic Journal of e-Learning, v. 2, n. 2, p. 313-320, 2004.

ZANELLA, A. V. Zona de desenvolvimento proximal: análise teórica de um conceito em algumas situações variadas. Temas em Psicologia [online], v. 2, n. 2, p. 97-110, 1994.

ZHANG, M. J. Assessing the performance impacts of information systems from the resource-based perspective: an empirical test of the indirect effect of IS. Journal of Business Strategies, v. 24, n. 2, p. 141-166, 2007.

ZHAO, Y.; HUEYSHAN, T.; MISHRA, P. Technology: Teaching and Learning: whose computer is it? Journal of Adolescent and Adult Literacy, v.
44, p. 348-355, 2001.

ZUANON, A. C. A. O Processo Ensino Aprendizagem na Perspectiva Das Relações Entre: Professor-Aluno, Aluno-Conteúdo E Aluno-Aluno. Revista Ponto de Vista, v. 3, n. 13, 2002. 